\title{
Correction to: A data-driven method for performance analysis and improvement in production systems with quality inspection
}

\author{
Jun-Qiang Wang ${ }^{1,2} \cdot$ Yun-Lei Song ${ }^{1,2} \cdot$ Peng-Hao Cui ${ }^{1,2} \cdot$ Yang $^{\mathrm{Li}^{1,2}}{ }^{\text {(i) }}$
}

Published online: 9 September 2021

๑) Springer Science+Business Media, LLC, part of Springer Nature 2021

\section{Correction to: Journal of Intelligent Manufacturing https://doi.org/10.1007/s10845-021-01780-5}

The original version of this article unfortunately contained a mistake. Under the header 'An event-based modelling method', the formula in the Proposition 1 appeared incorrectly as $\sum_{r=1}^{w} \int_{t_{r}^{h^{*}}}^{t_{h^{*}}^{h^{*}}} v_{n_{h^{*}}}^{h^{*}}(\tau, \vec{\Theta}, \vec{\sigma}) d \tau$. The formula should have appeared as shown below.

$$
\sum_{r=1}^{w} \int_{t_{r}^{t^{*}}}^{t_{r}^{h^{*}}+d_{r}^{h^{*}}} v_{n_{h^{*}}}^{h^{*}}(\tau, \vec{\Theta}, \vec{\sigma}) d \tau
$$

The original article has been corrected.
Publisher's Note Springer Nature remains neutral with regard to jurisdictional claims in published maps and institutional affiliations.

The original article can be found online at https://doi.org/10.1007/ s10845-021-01780-5.

Yang Li

pacpos.yli@gmail.com

1 Performance Analysis Center of Production and Operations Systems (PacPos), Northwestern Polytechnical University, Xi' an 710072, China

2 Department of Industrial Engineering, School of Mechanical Engineering, Northwestern Polytechnical University,

Xi'an 710072, China 